\title{
La responsabilidad objetiva en la protección del derecho del consumidor: ¿Es una cuestión de Estado?*
}

\author{
The objective responsibility in the protection of the right of the \\ consumer: Is it a matter of the State?
}

\begin{abstract}
RESUMEN
Anteriormente se entendía que las relaciones que surgían en las transacciones del mercado, eran competencia exclusiva del Derecho Privado; sin embargo la intervención estatal permitió regular por medio de leyes el ejercicio y desarrollo de la actividad económica, al igual que brindar las garantías para una óptima protección de los derechos a los consumidores. La promulgación de la Ley 1480 de 2011, se enmarca en esta nueva concepción jurídica, la cual frente a la responsabilidad objetiva, indica que sus efectos irradian a todas las partes intervinientes en la cadena de producción y comercialización de los bienes y servicios. El presente artículo de reflexión, busca analizar el desarrollo normativo y jurisprudencial de la responsabilidad objetiva en materia de protección al consumidor, así mismo, caracterizar el avance jurídico que ha tenido el tema a través del estudio de casos en el orden nacional e internacional y así evidenciar las fortalezas y falencias en materia de responsabilidad objetiva frente al derecho de consumo.
\end{abstract}

\section{PALABRAS CLAVE}

Responsabilidad objetiva, Estado, Derechos del consumidor, Daño, Garantías.

\begin{abstract}
Previously it was understood that the relationships that arose in the transactions of the market, were exclusive competence of the private law; however, state intervention made it possible to regulate by law the exercise and development of economic activity, as well as providing guarantees for the optimal protection of consumer rights, the enactment of Law 1480 of 2011, is part of this A new legal concept, which, in the face of objective liability, indicates that the effects of it radiate to all parties involved in the chain of production and marketing of goods and services. This article aims to analyze the normative and jurisprudential development of the objective responsibility in the matter of consumer protection, as well as to characterize the legal advance that has had the subject through the study of cases in the national and international order and thus evidence the strengths and shortcomings in the matter of objective responsibility towards the right of consumption.
\end{abstract}

\section{KEYWORDS}

Objective responsibility, State, Consumer rights, Damage, Guarantees.

\section{JORGE MIGUEL GUEVARA FRAGOZO}

Abogado de la Universidad Santo Tomás. Especialista en Derecho Administrativo de la Universidad Santo Tomás. Especialista en Contratación Estatal de la Universidad Externado de Colombia. Actualmente candidato a Magíster en Derecho de la Universidad Sergio Arboleda Seccional Santa Marta. jorgemiguelgf@hotmail.com

* Esta investigación se desarrolló en el marco del Programa Consuma Caribe y contó con la dirección temática del doctor Edimer Latorre Iglesias. 


\section{INTRODUCCIÓN}

Cuando nos referimos al término de responsabilidad, se hace alusión al deber que se Los orígenes de la responsabilidad objetiva tiene de resarcir un daño causado. Esto in- se encuentran marcados por el desarrollo cluye la relación conceptual entre el daño, el jurisprudencial de Roger J. Traynor (Ministro causante del daño y la víctima; al igual que la de la Corte Suprema de California durante 30 configuración de los elementos que generan años), el cual afirmaba que este tipo de resla responsabilidad de reparar, tales como el ponsabilidad era un asunto que concierne hecho antijurídico; la presencia del daño en Estado, por cuanto todas las políticas públila conducta realizada, la cual indica el nexo cas destinadas a reglamentar las relaciones cearácter privado, debían ser justas y genesabilidad que puede ser subjetiva u objetiva rar un bienestar social.

$y$ se atribuye a un agente dañar 2014, p.105).

Con fundamento en el principio jurídico que establece que nadie puede dañar a otro $y$ en caso de ocasionar un perjuicio este debe ser resarcido, la responsabilidad puede clasificarse en subjetiva y objetiva. Estas se diferencian en el elemento de culpa/dolo, asegurando que mientras la responsabilidad subjetiva requiere de la configuración de la culpa/dolo para indemnizar a la víctima por los perjuicios ocasionados, la responsabilidad objetiva se materializa con la ausencia de la culpa/dolo, es decir, basta con la existencia del riesgo que se transforma en daño y ocasiona un detrimento para que surja la obligación de resarcir.

Mosset (1993, pp.28-29) indica, que si bien existen diferencias entre las clases de responsabilidades, su fin último es reparar el daño ocasionado, dado que el deber de indemnizar a la víctima es prioritario en el sis- De igual forma, el Estado a través de sus ins- tituciones políticas como las Altas Cortes, y pectiva para reconstruir cómo se construyó aplicando los principios de la Carta Magna, el concepto y cómo ha sido su aplicación. ha desarrollado un andamiaje jurispruden-

cial en materia de responsabilidad objetiva, Por último se realizará una fase exploratoria cuya finalidad es la de contribuir por vía le- y descriptiva de Derecho Comparado sobre gal, doctrinal y analogía de la jurisprudencia el empleo de la figura de responsabilidad

extranjera a la protección de los derechos objetiva en la protección de los derechos del consumidor.

Con la expedición de la Ley 1480 de 2011, el legislador pretendió ejercer control sobre las relaciones de consumo, para brindar las garantías necesarias al libre ejercicio y protección de los derechos del consumidor. Es así como esta normatividad analiza el tema de la responsabilidad objetiva, la cual recae sobre los productores y proveedores que según la ley se encuentran obligados a responder po la calidad, idoneidad y seguridad de los productos ofrecidos en el mercado.

Teniendo en cuenta esto, la presente investigación pretende analizar el concepto de responsabilidad objetiva en el marco de la protección de los derechos del consumidor, así como establecer la regulación del Estado a través de la jurisprudencia nacional con analogía de casos extranjeros.

La metodología empleada se dará a través de una búsqueda documental y bibliográfica para construir una teoría a partir de la base cientifica encontrada. Se hará énfasis en el análisis de los componentes teóricos predominantes que constituyen la figura de la responsabilidad objetiva en el derecho de consumo, y se realizará una revisión en retrosdel consumidor en países latinoamericanos, partiendo del análisis de trabajos académicos, modelos y jurisprudencia, con el fin de confrontarlos con la figura creada en nuestro país.

1. Antecedentes de la irrupción de la sociedad del riesgo

La reglamentación legal del tema de responsabilidad dentro de la sociedad, es de gran importancia, dado el desarrollo industrial y consumista en el que nos encontramos inmersos, originando así lo que se conoce como sociedad de riesgo, concepto que explica Gutiérrez, indicando que esta colectividad se encuentra determinada por nuevos riesgos causados por el incremento tecnológico de las empresas y las cadenas de producción, distribución y consumo (Gutiérrez Santiago, 2006, p.22)

En el mismo sentido Díez-Picazo (1979) establece que la transformación paulatina de la sociedad técnica a través de los años, implica una serie de efectos en la dependencia y uso de la tecnología por parte de los consumidores, lo cual conlleva a que paralelamente a esto, nazcan nuevos riesgos, en razón del proceso de modernización de la sociedad industrial, lo que potencia significativamente 
un sistema de daños en contra de la cadena Esta práctica generó gran controversia social básica del mercado, esto es, de los consumi- dado que el análisis de la teoría de la respondores (p.732).

De manera pues, que es necesario que las normas desarrolladas en pro de la defensa y protección de los derechos del consumidor sean acordes para dar las respuestas a las necesidades de seguridad y responsabilidad frente a daños ocasionados por los productores de bienes y servicios (Gutiérrez Santiago, 2006, pp.35-36).

En este orden de ideas es pertinente indicar que el derecho anglosajón fue uno de los sistemas jurídicos que desarrolló la responsabilidad frente a los productos defectuosos comercializados en el mercado y representó un reto para los operadores de justicia en determinar los sujetos sobre los cuales recaería la responsabilidad, de acuerdo a la teoría contractual llamada privity of contrac y la stricti liability o la denominada responsabilidad objetiva.

Inicialmente, los jueces ingleses analizaban la responsabilidad desde el ámbito contractual en las relaciones de consumo, por lo que en la mayoría de casos se beneficiaba el productor (Woolcott, 2007, p.127). De tal manera que los productores y distribuidores encontraban en el sistema normativo una ventana de actuación que iba en detrimento de los derechos del consumidor, lo que conllevaba a que los consumidores no reclamaran algún tipo de indemnización por los daños ocasionados al adquirir un producto defectuoso en el mercado (Munar, 2013, p.177). dado que el análisis de la teoría de la responsentaba una protección a los productores una falta de garantías a los consumidores, es decir, a toda la sociedad se dejaba desprotegida, pues se endilgaba que de acuerdo al principio caveat emptor, la responsabilidad de la calidad, idoneidad y seguridad de los productos era exclusiva del comprador (COleman, 2010, p.407).

De la Maza explica la tesis del caveat emp tor de acuerdo al sistema del Common Law, aduciendo que en la etapa de negociación contractual las partes deben protegerse a mismas y no se encontraban en la obligación de comunicar a su contraparte, alguna información relevante para determinar el consentimiento de forma correcta en un negocio jurídico (2009, p.34)

En este sentido el Derecho norteamericano incursionó de forma disruptiva en el desarrollo de la stricti liability o responsabilidad objetiva en el derecho del consumo, donde el productor se considera responsable frente a los consumidores siempre y cuando se le mpute un daño generado por la compra de un producto defectuoso (Coderch, Piñero \& Rubí, 2003, p.6)

Esta teoría se ha resaltado al momento de emitir los fallos, entre los cuales se menciona el caso entre MacPherson vs. Buick Motors en 1916, sentencia que marcó un punto trascendental en la aplicación judicial de teoría de stricti liability, donde se condena al fabricante de automóviles por el desperfecto de una rueda, que generó un perjuicio a la victima sin existir un vínculo contractual entre ambos, pero se configura la tesis de peligro inherente al producto que representa un riesgo al consumidor. Esta tesis se desarrollaba en los casos en los que la responsabilidad y los medios de prueba recaían en el fabricante por la producción de productos defectuosos que representaban un riesgo la seguridad del comprador, por cuanto el fabricante controla la cadena de producción Villalba Cuéllar, 2014, p.19)

Sin embargo, el caso más significativo fue de Escola vs. Coca Cola Bottling en 1944, sentencia producida por el juez Roger Traynor, que manifiesta la responsabilidad absoluta que tiene el productor al colocar un producto en circulación en el mercado, con el conocimiento de que este puede causar un daño los consumidores por presentar defectos de fábrica.

Aquí Traynor manifiesta que la responsabilidad recae sobre el fabricante, dado que los consumidores no tienen los conocimientos necesarios para indicar que el producto adquirido está en óptimas condiciones y cumple con las calidades que no atenten contra su seguridad, por lo cual es injusto imponerle una carga probatoria que demuestre el daño si desconocen el proceso de producción y comercialización de los productos (Escola vs. Coca-Cola Bottling Co., 1944).

Bajo esta premisa las sentencias emitidas en el Derecho norteamericano, permitieron la construcción de algunos preceptos que señalan la responsabilidad sin culpa por los productos defectuosos circulantes en el mercado. Para 1960 el litigio entre Henningsen vs. Bloomfield Motors Inc., permitió la creación de la garantía de comerciabilidad aplicada a terceros que no hayan adquirido el producto, admitiendo así su pertinencia a todos los productos.

Ya en el año de 1965 se promulga la Restatement of torts, sección $402 \mathrm{~A}$, jurisprudencia que contempla y desarrolla el concepto de daños por productos defectuosos, tesis que evolucionaron de forma más específica en 1997, año en el que se expide la Restatement of torts: product liability; jurisprudencia que abarca de forma determinada el concepto de defecto y sus clasificaciones, asi como el deber de información y las reglas de causalidad (Woolcott, 2007, pp.129-132).

Acerca del concepto de información, Iñigo De la Maza manifiesta la relevancia que tiene este deber en la etapa precontractual, especialmente en la formación de los contratos civiles, indicando que este se estructura por un supuesto de hecho y una consecuencia jurídica. Frente al análisis del supuesto de hecho en el deber de información se tiene en cuenta la acción de una de las partes en no proporcionar información acerca del negocio jurídico a la otra, la cual se presenta bajo ciertas eventualidades tales como: la Ignorancia, el conocimiento y la reticencia (2009, p.62).

Sobre estas eventualidades se define lo siguiente: 
a) La ignorancia se caracteriza por el desco- 374 , la cual se considera como un mecanisnocimiento de información vital del ne- mo idóneo implementado en la política cogocio jurídico por alguna de las partes, lo munitaria de protección al consumidor, para cual conlleva a que se celebre un contra- endilgar responsabilidad civil por productos to, donde seguramente si la parte afecta- defectuosos (Díaz-Ambrona Bajardí, Hernánda tuviera la información real y completa dez Díaz-Ambrona, Pous De la Flor \& Tejedor no hubiera pactado o negociado ese mis- Muñoz, 2012, p.439). mo contrato.

b) El conocimiento se caracteriza porque Así esta directriz se compone de una serie esta parte si tiene conocimiento sobre la de artículos que establecen los preceptos información que su contraparte desco- que rigen el ámbito de la responsabilidad noce, lo cual es determinante al momen- por productos en la Comunidad Europea. De to de celebrar el negocio jurídico.

c) La reticencia se caracteriza por el hecho de que una de las partes, conociendo cierta información acerca del negocio jurídico, no la da a conocer a la otra, que acuerda bajo parámetros contractuales distintos a los que realmente deberían ser (De la Maza Gazmuri, 2009).

Analizando la estructura del deber de información, vemos que la violación al mismo genera una consecuencia jurídica perjudicial para aquella parte que lo contraviene, dado que se encuentra en la obligación de indemnizar los daños causados a su contraparte. Sin embargo, esta indemnización va ligada al hecho de que las consecuencias estén relacionadas de forma directa con la reticencia de aquella parte que conocía información relevante en el negocio jurídico pero no quiso suministrarla (2009, pp.63-65).

El sistema de responsabilidad en el marco de derecho de consumo, ha sido implementado dentro de las directrices de la Comunidad Europa, tal como es el caso de la Directiva objetiva en materia del consumo, especialmente por productos defectuosos, a través del Real Decreto Legislativo 22 de 1994 de la Directiva 374 de la Comunidad Europea.

Sin embargo esta norma fue derogada por el Real Decreto Legislativo 1/2007 del 16 de noviembre, en el cual se constituye el TRLGCU (texto refundido de la Ley Genera para la Defensa de los Consumidores y Usuarios), la cual adopta las directrices comunitarias sobre los preceptos contractuales que deben regular las relaciones comerciales pactadas a distancia o fuera de los establecimientos de comercio; así como la reglamentación que se da frente a la garantía por la enajenación de productos comercializados para el consumo; al igual que la incorporación de la responsabilidad civil derivada por el daño causado por un producto defectuo-

A su vez la Ley 3 de 2014 del 27 de marzo, reforma el TRLGCU teniendo en cuenta la Directiva 2011/83/EU, la cual tiene como objetivo consolidar los preceptos normativos internos referentes a los contratos celebrados con los consumidores, que permitan crea un orden legal común en Europa para fortalecer la seguridad jurídica y el mercado interno. De manera pues que esta reforma analiza los contratos pactados a distancia y las demás formas de contratación; precisa los conceptos de consumidor, empresario, contrato a distancia, establecimiento mercantil, entre otros, con la finalidad de armonizar las diferencias que existen sobre los conceptos en los Estados miembros.
Díez-Picazo explica que este tipo de responsabilidad (objetiva) no incluye la culpa o negligencia de los actores a quienes la norma y el consumidor le atribuyen la responsabilidad, puesto que lo que se busca es probar los defectos surgidos en los productos comercializados en el mercado de acuerdo a la seguridad y calidad que deben tener, y no los elementos subjetivos (Díez-Picazo, 1999, p.144).

En Latinoamérica el ordenamiento jurídico brasileño incluye la responsabilidad objetiva frente a los derechos del consumidor, en los casos de productos defectuosos y prestación un servicio defectuoso (Vásquez Pérez, 2015, p.31).

2. Responsabilidad objetiva en el Derecho del Consumo en Colombia

La evolución de la responsabilidad objetiva en Colombia ha sido paulatina, así el Decreto 3466 de 1982 contemplaba ciertas acciones de orden administrativo que permitían el pago de perjuicios ocasionados por la falta de calidad e idoneidad de los bienes y servicios comercializados en el mercado.

De igual forma, este criterio fue ampliado jurisprudencialmente por la Corte Constitucional, al realizar un análisis con base en el artículo 78 de la Carta Magna, del deber que le correspondía al consumidor de probar un defecto en un producto para establecerse responsabilidad de los fabricantes, enunciando: 
. el defecto cuya prueba compete al perjudicado, no es el error de diseño o intrínseco del producto, cuyo conocimiento difícilmente puede dominar o poseer el consumidor; lo es la inseguridad que se manifiesta con ocasión del uso al cual está destinado. Probado el defecto resulta razonable suponer que la responsabilidad corresponde al empresario que controla la esfera de la producción, la organiza, dirige y efectúa el control de los productos que hace ingresar al mercado y, por ende, para liberarse debe éste a su turno demostrar el hecho que interrumpe el nexo causal. (2000)

Con base en lo anterior la Corte enfatizó en el deber de seguridad que asumen los productores y distribuidores en la comercialización de un producto en el mercado. Aquí se evidenció la relación desigual que existe entre los consumidores y el productor o distribuidor, indicando que la responsabilidad por productos defectuosos, es objetiva, por cuanto su fundamento está basado en el riesgo, hecho que obliga el deber de ofrecer productos en óptimas calidades y garantías a la seguridad e integridad física, imposibilitando la exoneración del productor por actuar con diligencia y cuidado.

Con la expedición de la Ley 1480 de 2011 se busco complementar el sistema de responsabilidad en materia del consumidor en tanto la finalidad normativa es la protección integral del mismo, imponiendo así una obligación de seguridad a los productores distribuidores para con los usuarios en la co- mercialización de bienes y servicios con base en el precepto constitucional emanado del artículo 78 (Villalba, 2012, p.42).

Es así como el artículo 3 del Nuevo Estatuto del Consumidor indica la voluntad del legislador que reconoce la seguridad como un derecho que tiene el consumidor a no sufri un daño a su integridad por el uso de un producto, así como lo establece el Principio de Seguridad en el artículo 1 de la mencionada

Teniendo en cuenta esto, la seguridad se considera un deber que busca estar a la altura de los requerimientos que propenden por una satisfacción mínima de las necesidades básicas de las personas, por parte de aquellos productores que ingresan al mercado un bien o servicio para comercializarlo (CalaisAuloy \& Steinmetz, 2006, p.301).

Analizando el concepto de seguridad, se encuentra que su inclusión en la normatividad del consumidor ha sido novedad, resaltando que esta se considera como la

Condición del producto conforme con la cual en situaciones normales de utilización, teniendo en cuenta la duración, la información suministrada en los términos de la presente ley y si procede, la puesta en servicio, instalación y mantenimiento, no presenta riesgos irrazonables para la salud o integridad de los consumidores. En caso de que el producto no cumpla con requisitos de seguridad establecidos reglamentos técnicos o medidas sanita- rias, se presumirá inseguro. (Congreso de la República de Colombia, 2011)

De manera pues que la inobservancia y no cumplimiento de los requerimientos mínimos de seguridad que debe tener un produc to, que ocasionen un perjuicio a los consumidores o sus bienes en razón de su desperfecto, genera una responsabilidad por daños por parte del productor, la cual obliga al consumidor como directamente perjudicado, a probar el defecto del bien sin la obligación de señalar las posibles causas que generaron este hecho, invirtiendo así la carga de la prueba al productor o distribuidor del bien servicio (Giraldo López, 2014, p.60).

\section{Responsabilidad por} producto defectuoso

Antes de adentrarse al contexto de la estructura normativa de la responsabilidad por producto defectuoso en Colombia, es necesario entender que esta va ligada íntimamente a concepto de obligación de seguridad, que debe darse en las relaciones de consumo.

Así encontramos que el concepto de obligación de seguridad fue concebida desde el año 1911 por la jurisprudencia francesa la cual admitió la existencia de ciertas conductas que propendían la protección de los contratantes frente a los daños que pudieran ocasionarse a la integridad física y un menoscabo al patrimonio. Esta concepción se dio gracias a la interpretación de la Cour de Cassation acerca de los deberes y responsabilidades que debían darse en el contrato de transporte, concluyendo que el transportador no se encontraba obligado solamente a trasladar a personas de un lugar a otro, sino que además debía conducirlos de forma sana, no arriesgando su integridad física, lo que generó que el deber de seguridad permitiera incluir en la responsabilidad contractual aquellos daños que por tradición habían sido de la esfera de la responsabilidad extracontractual, exonerando al perjudicado de probar el daño ocasionado, trasladando la carga probatoria al transportador, el cual solo podría ser eximido de culpa por una causa ajena a él (Rodríguez Olmos, 2013, pp.327-329).

Para el caso de Colombia, el concepto de obligación de seguridad fue acogido en el año de 1983 por la Corte Suprema de Justicia, la cual analizó el contrato de transporte, determinando que el transportador se encuentra obligado frente al personal que transporta a trasladarlos al lugar acordado de forma sana y respetando su integridad física (Corte Suprema de Justicia, Sala de Casación Civil, 1938).

De igual forma la Corte Suprema ha definido esta obligación de seguridad argumentando

aquella en virtud de la cual una de las partes en la relación negocial se compromete a devolver sanos y salvos -ya sea a la persona del otro contratante o sus bienes- al concluir el cometido que es materia de la prestación a cargo de dicha parte estipulada, pudiendo tal obligación ser asumida en forma expresa, venir impuesta por la ley en circunstancias especiales o, 
en fin, surgir virtualmente del contenido 2. Los producidos a una cosa diferente al propio del pacto a través de su entendimiento integral a la luz del postulado de la buena fe. (Corte Suprema de Justicia, Sala de Casación Civil, 1993)

Con base en lo anterior, se indica que para las legislaciones francesa y colombiana e deber de seguridad se dio gracias a los problemas de orden contractual, que permitieron extender el alcance y cobertura de la prestación del servicio por parte del deudor y la responsabilidad que este asume frente a los consumidores (Espinoza Apráez, 2015, pp.378-379)

El Nuevo Estatuto del Consumidor o la Ley 1480 de 2011 replantea el concepto de la obligación de seguridad y lo relaciona con el daño, explicando que esta procede de la responsabilidad que tiene el fabricante o distribuidor frente a los consumidores por la producción y comercialización de bienes y servicios defectuosos que atenten contra la integridad y seguridad de los consumidores y sus bienes. De tal manera que el daño de producto debe ser probado por el consumidor afectado, así como la relación jurídica entre las causas del perjuicio y el resultado dado (Congreso de la República de Colombia, 2011)

El artículo 20 de la mencionada ley expresa el concepto de daño entendiendo que este se constituye cuando se da:

1. La muerte o lesiones corporales, causadas por el producto defectuoso; producto defectuoso, causados por e producto defectuoso (Congreso de la República de Colombia, 2011).

Villalba manifiesta que se configura la responsabilidad por productos defectuosos el diseño o la información de un producto, que genera un daño a la integridad física de los consumidores o a su patrimonio. De manera que se requiere la existencia real contra del consumidor para que se determine la responsabilidad del mismo $(2014$ p.22)

Con base en esto es importante manifestar que no se debe confundir el defecto de un producto que pueda generar un perjuicio, frente a la eventualidad de que este no funcione de la manera correcta, ya que en e último caso, la normatividad del consumidor prevé otro contexto de aplicación, como lo es el tema de la garantía de productos de acuerdo a su calidad e idoneidad (Larrosa, 2011, p.215).

De igual forma se cae en la confusión cuando se involucran los conceptos de productos defectuosos y productos nocivos. En estos casos se tiene en cuenta que el primero surge por el daño causado por las acciones u omisiones de un fabricante o distribuidor, mientras que el segundo representa un perjuicio real al consumidor y su seguridad por su esencia, como por ejemplo los cigarrillos que por su consumo a largo plazo pueden cuando existe un error en la producción, en un perjuicio ocasionado por un producto en ocasionar enfermedades respiratorias graves como el cáncer de pulmón que puede llevar a la muerte de una persona.

Sin embargo es importante tener en cuent que un producto nocivo puede convertirse n un producto defectuoso, siempre $y$ cuando se omita el deber de información para uso, que está a cargo de los productores y distribuidores sobre su peligrosidad, pues violenta el principio de seguridad que ampara al consumidor (Parra Lucán, 1990, pp.501 502).

Para la Ley 1480 de 2011, el producto es defectuoso cuando:

Artículo 5 numeral 17. Producto defectuoso es aquel bien mueble o inmueble que en razón de un error el diseño, fabricación construcción, embalaje o información, no ofrezca la razonable seguridad a la que toda persona tiene derecho. (Congreso de la República de Colombia, 2011)

Frente al concepto anterior cabe manifestar que Villalba (2014) realiza una crítica al tratamiento de defecto como error que le da la Ley 1480 , dado que reviste de subjetividad Ia responsabilidad a cargo del proveedor o distribuidor, admitiendo la culpa del operador, hecho que es inconcebible dado que los defectos surgidos en los productos comercializados en el mercado, deben gozar de una seguridad para los usuarios, generada por un control e inspección en la cadena de produc ción, características propias de un sistema e responsabilidad objetiva (Villalba Cuéllar 2014, pp.23-24).

\section{Defectos en el Estatuto del Consumidor}

Oviedo Albán explica que de acuerdo a la normativid se obliga para con el comprador a realizar la tradición y entrega de la cosa, así como la responsabilidad que tiene de subsanar la evicción y los vicios redhibitorios. Para el caso de los vicios redhibitorios se indica que para su configuración desde la perspectiva material es necesario cumplir con dos condiciones las cuales son: a) darse un defecto en el producto y b) en razón de este defecto verse implicado el funcionamiento normal del bien (2015, pp.53-56).

Desde la percepción doctrinal se establece que el bien es defectuoso cuando el desperfecto implica un mal funcionamiento del mismo, lo que no permite el uso normal por parte del comprador configurándose así un vicio redhibitorio (Oviedo Albán, 2015, p.56).

Baudry-Lacantinerie y Saignat explican que no se debe confundir la diferencia entre los vicios redhibitorios y el error, dado que se configura un vicio en el consentimiento cuando cae en las cualidades del bien, por el contrario existe un defecto cuando el bien presenta un mal funcionamiento, lo cual no permite que el comprador use el producto de acuerdo a la finalidad para lo que adquirió (1908, p.422)

De acuerdo a la noción funcional se indica que el vicio redhibitorio implica una serie de condiciones que afectan el normal funcionamiento del bien y al vendedor de la cosa que 
celebró un contrato de venta con un deter- artículo 5 numeral 17 explica el concepto de minado comprador. De manera pues que se producto defectuoso afirmando:

establece la existencia del defecto en el bien,

cuando esta lo hace inidóneo para el uso que motivó al comprador a adquirir el producto (Ghestin, 1983)

Los vicios redhibitorios cumplen ciertas características, enunciadas por el artículo 1915 del Código Civil, las cuales son:

1. Haber existido al tiempo de la venta.

2. Ser tales, que por ellos la cosa vendida no sirva para su uso natural, o solo sirva imperfectamente, de manera que sea de presumir que conociéndolos el comprador no la hubiera comprado o la hubier comprado a mucho menos precio.

3. No haberlos manifestado el vendedor, $y$ ser tales que el comprador haya podido ignorarlos sin negligencia grave de su parte, o tales que el comprador no haya podido fácilmente conocerlos en razón de su profesión u oficio (Congreso de Colombia, 1887).

Analizando estas características se infiere que el vicio debe ser oculto o ignorado al comprador, hecho que se da en los casos en que el vendedor no entrega la información veraz y real del negocio jurídico al comprador o cuando este ignora en razón de su oficio el mismo, por lo tanto no se puede considerar como vicio redhibitorio aquel que el vendedor dé a conocer o que el comprador visibilice en la inspección del bien.

En materia de responsabilidad por productos defectuosos, la Ley 1480 de 2011 en su ...es aquel bien mueble o inmueble que en construcción, embalaje o información, no ofrezca la razonable seguridad a la que toda persona tiene derecho. (Congreso de la República de Colombia, 2011)

El defecto en los productos puede darse seún la normatividad por:

- Error de diseño.

- Error de fabricación.

- Error de construcción.

- Error de embalaje.

- Error de información

Se entiende por defecto de diseño aquel que versa sobre la creación del bien, su configuración y su belleza. Coderch et al., expresa que se tienen en cuenta dos reglas para indicar si un producto presenta defectos de diseño, como lo son el denominado test de la expectativa razonable por parte del consumidor, tesis propia de la doctrina y normativa de la Unión Europea y España, en la cual se analiza el defecto del producto desde la perspectiva del pensamiento del consumidor, es decir, que este no cumple con el ideal que motivó al usuario a adquirir el bien induciéndole a un error causándole un perjuicio.

Por otra parte se encuentra la regla del riesgo-utilidad, tesis desarrollada por los operadores judiciales estadounidenses, que manifiesta que el diseño de un producto puede ser defectuoso cuando los riesgos de perjuirazón de un error el diseño, fabricació cios podrían ser previsibles empleando un diseño alternativo, que brindara una seguridad al consumidor (Responsabilidad civil de fabricante y teoría general de la aplicación del Derecho (Lawe nforcement), 2003, p.15)

Continuando con el estudio de las clase de defectos, se encuentran aquellos denominados defectos de fabricación, concepto que explica Gutiérrez (2011) argumentando que estos son errores que se presentan en creación de productos por parte de un humano o la máquina encargada de los procesos de producción, lo cual da como resulto una serie de desperfectos en la misma (p.678).

En este mismo orden de ideas se encuentra que los defectos de construcción aplican para las acciones $u$ omisiones realizadas a bienes inmuebles en un proceso de construcción, los cuales se encuentran viciados por la inclusión de un desperfecto, que trae como consecuencia un daño al consumidor, que genera responsabilidad a los productores y proveedores.

De igual forma frente a los defectos surgidos por el embalaje, es pertinente menciona que este hecho tiene como consecuencia la poca preservación de la vida útil del bien, o que conlleva a que se modifiquen los elementos esenciales del producto, hasta el punto que estos puedan convertirse en inseguros para el consumidor.

por último, pero no menos importante, los defectos presentados por la falta de informa- ción. Esta tesis considera que el producto comercializado en el mercado no posee desperfecto alguno, pero por el desconocimiento de la información por parte del consumidor sobre el uso y las contraindicaciones de un determinado bien o servicio, se produce un daño a la integridad física del usuario y sus bienes. El impase o defecto se subsana mediante el deber de aviso que tiene el productor sobre la calidad, idoneidad y efectos que tienen los bienes y servicios, tal como son los casos de las bebidas alcohólicas donde la etiqueta incluye la reseña que es un producto nocivo para la salud (Woolcott, 2007, p.121).

Teniendo clara la clasificación construida en torno a los conceptos de producto defectuoso, se analizan a continuación los elementos que configuran la responsabilidad por productos defectuosos. En primer lugar encontramos que se considera la responsabilidad por productos defectuosos como una responsabilidad de mercado de acuerdo a la jurisprudencia emitida por la Corte Constitucional:

La responsabilidad del productor y del distribuidor surge ex constitutione y puede por ello ser deducida por el consumidor del producto o el usuario, con independencia de que exista o no un vínculo contractual directo con los primeros. En este sentido, las garantías atingentes a la calidad o idoneidad de los bienes y los servicios, no se ofrecen exclusivamente al primer adquirente; ellas se disponen frente a la categoría de los consumidores 
y usuarios. El productor profesional produce para el mercado, se beneficia del mercado y debe responder ante el mercado. En este caso, el mercado está constituido por los consumidores y usuarios. La responsabilidad de mercado -secundada por la Constitución y la ley-, no contractual, acredita la reivindicación igualitaria que ha querido la Constitución introducir bajo el concepto de consumidor o usuario. (Corte Constitucional de Colombia, 2000)

De acuerdo a esto se concluye que si bien la responsabilidad por productos defectuosos es un acápite de la responsabilidad civil, esta se enmarca como una responsabilidad significativa, dado que no requiere del nexo derivado de la existencia de un contrato para el surgimiento de la obligación.

Asimismo se establece que la responsabilidad por producto defectuoso es una responsabilidad objetiva, dado que al crear un producto los fabricantes generan unos riesgos al comercializarlos en el mercado, por cuanto ellos son los que reciben los beneficios económicos de la actividad de producción de bienes y servicios y poseen la información correspondiente a la cadena de producción, dejando en desventaja a los consumidores (Mosset \& Wajntraub, 2008, p.244).

Igualmente el Estatuto del Consumidor prevee la responsabilidad solidaria de los productores y distribuidores frente a productos defectuosos comercializados en el mercado. Tamayo lo explica enunciando: ...una responsabilidad solidaria de todas las personas que participen en la cadena de producción y distribución del producto da ñino, frente al tercero, consumidor o no, que finalmente sufra el daño como consecuencia del defecto o falta de calidad del producto. En esta forma, el fantasma de la diferencia entre responsabilidad contractual y extracontractual tiende reducirse $o$ a eliminarse en este tipo de daños. (Tamayo, 2007, p.117)

\section{Eximentes de responsabilidad de los pro-} ductores y proveedores

El régimen de responsabilidad por productos defectuosos establecido en el derecho de consumo colombiano, estipula taxativame te en la ley unas causales de exoneración de productor, las cuales analizan un factor común tal como lo es un suceso extraño aislado del actuar diligente en la creación y fabricación de los productos por parte del fabrican-

En el contexto de protección a los derechos del consumo, se genera una responsabilidad objetiva por parte del productor hacia consumidor por los daños ocasionados por un bien o servicio defectuoso, donde se aplica el principio de que quien configura un perjuicio a otro debe indemnizarlo, en razón de que esta persona no estaba en la obligación moral y legal de soportar un menoscabo de sus derechos (Giraldo López, 2014, p.58).

El Estatuto del Consumidor prevé unas causales explícitas que exoneran de la responsa- bilidad a los fabricantes y distribuidores, tal como lo manifiesta el artículo 22

1. Por fuerza mayor o caso fortuito;

2. Cuando los daños ocurran por culp exclusiva del afectado;

3. Por hecho de un tercero;

4. Cuando no haya puesto el producto en circulación;

5. Cuando el defecto es consecuencia directa de la elaboración, rotulación o empaquetamiento del producto conforme a normas imperativas existentes, sin que el defecto pudiera ser evitado por el productor sin violar dicha norma;

6. Cuando en el momento en que el producto fue puesto en circulación, el estado de los conocimientos científicos $y$ técnicos no permitía descubrir la existencia del defecto. (Congreso de la República de Colombia, 2011)

La configuración de estas causales enunciadas en la Ley 1480 de 2011, permite deducir que la responsabilidad que surge por el desperfecto de los productos es objetiva, dado que no pueden ser atribuidas a los productores y proveedores por contemplar causas extrañas a su voluntad, a excepción que no pueden exonerarse de la responsabilidad alegando un obrar diligente en el proceso de producción

Acorde a esto vemos que en el contexto de la responsabilidad objetiva por los desperfectos en los productos, no se tiene en cuenta que los fabricantes y distribuidores hayan actuado con culpa, pues solo basta con que se compruebe el nexo causal existente entre la causa y la existencia del daño, así como el defecto del producto para que se atribuya la responsabilidad (Espinoza Apráez, 2015).

\section{. Derecho Comparado:}

\section{Legislación española}

Anteriormente los casos de responsabilidad por daños generados por el uso de bienes $y$ servicios defectuosos por parte de los consumidores, se analizaban desde la óptica de los principios y reglas del Código Civil Español concernientes a la responsabilidad contractual y extracontractual, con el objeto de resarcir los perjuicios causados (Vázquez Bulla, 2014, p.718)

El avance constante del mercado y los procesos de industrialización, trajeron como consecuencia que los conceptos extraídos de la normatividad civil quedaron cortos para abarcar un sistema de responsabilidad integral en favor de los consumidores, considerados la parte más vulnerable en las relaciones económicas.

De manera pues que la promulgación de la Ley 26 de 1984, denominada "Ley General para la defensa de consumidores y usuarios", sistematizó ciertos postulados sobre el derecho del consumo, que manifiestan que todo daño o perjuicio causado por la adquisición de bienes y servicios que logre ser probado por el consumidor, debe ser resarcido de acuerdo al principio de responsabilidad del fabricante teniendo en cuenta la configuración de la culpa 
Sin embargo el régimen de responsabilidad que desarrollaba la Ley 26 de 1984, no garantizaba una protección integral a los consumidores, dado que al atribuir la responsabilidad a los productores debía estimarse el elemento de culpabilidad, por lo que el legislador aunó sus esfuerzos para expedir la Ley 22 de 1994, la cual buscaba endilgar la responsabilidad objetiva de los productores, teniendo en cuenta los daños causados por el uso de bienes y servicios defectuosos.

Es de anotar que la expedición de la Ley 22 de 1994 incluyó preceptos normativos instaurados en la Directiva 85/374 de la Comunidad Europea, sobre los temas de responsabilidad objetiva del fabricante, en los casos de productos defectuosos comercializados en el mercado y adquiridos por el consumidor. Asi la directriz explica el concepto de fabricante, explicando que este es la persona que manufactura un bien o servicio, y por este hecho adquiere una responsabilidad frente al consumidor al igual que el productor de materias primas, el que establezca el nombre, distintivo o signo en el producto e importador de los mismos por los daños ocasionados por productos defectuosos (Vázquez Bulla, 2014, p.722)

Con base en lo anterior, se indica que la Comunidad Europea insertó los principios doctrinales y jurisprudenciales frente a la responsabilidad por productos defectuosos de la legislación norteamericana, donde han desarrollado una serie de defectos atribuibles al productor tales como:
Defecto de fabricación: El cual se caracteriza por el hecho de que los bienes y servicios no establecen la seguridad ofertadas por los demás productos de igual denominación

Defecto de diseño: El cual se caracteriza por tener un desperfecto o fallo industrial desde el momento en que se concibe la creación del producto.

Defecto de información: El cual se caracteriza por no ofrecer al consumidor la información precisa acerca del uso, manipulación y consumo de un determinado bien y servicio (Vázquez Bulla, 2014 p.723)

A su vez el Real Decreto Legislativo 1/2007 del 16 de noviembre por la cual se da el texto refundido de la Ley General para la Defensa de los Consumidores y Usuarios y otras leyes complementarias, analiza los preceptos generales determinados por las directrices comunitarias acerca de las disposiciones aplicables a los contratos que surgen entre los consumidores y empresarios, así como as regulaciones a las relaciones comerciales que se dan en la distancia o en lugares distintos a los establecimientos del comercio. De igual forma esta normatividad pretende armonizar los preceptos legales de orden nacional en materia de protección a los derechos del consumidor con la legislación comunitaria.

Asimismo la Ley 3 de 2014, incluyó en la legislación española los preceptos establecido en la Directiva 83 de 2011, la cual regula e desarrollo y aplicación de los contratos que se realizan en el mercado con los consumidores y usuarios, reforzando la información atinente a las obligaciones precontractuales que se requieren para formalizar un contrato. De manera pues, que los productores y empresarios están en la responsabilidad de enunciar a los consumidores de forma clara as condiciones para los contratos de depósitos y demás garantías financieras, así como de la existencia de una garantía legal para los bienes adquiridos, los servicios postventa y las garantías comerciales que se concedan en razón de las relaciones de consumo creadas.

Para los casos especiales como los contrato de suministro de contenido digital, se obliga al empresario a informar de diversas maneras el uso del servicio, así como el deber de informar sobre cualquier limitación técnica que tenga el producto, tal como la protección mediante el trámite de derechos digitales, la interoperabilidad de los aparatos y programas de contenido digital. De igual forma, en los contratos a distancia las exigencias de información, incluyen limitaciones técnicas algunos medios comunicativos, lo cual obliga al empresario a direccionar al consumidor a fuentes de información confiables y veraces (Vázquez Bulla, 2014, p.724).

A su vez la Ley 3 de 2014 reglamenta los parámetros formales del contrato a distancia y de aquellos que se solemnizan en un lugar distinto de los establecimientos de comercio, lo cual obliga a los sitios comerciales en la web, a informar de forma clara y comprensible, antes de que el consumidor inicie su pro- ceso de compra, si tienen alguna limitación en el suministro de productos y las opciones de pago que aceptan para realizar la compra.

\subsection{Derecho Comparado}

Legislación argentin

Realizando un análisis comparativo frente el desarrollo de la responsabilidad objetiva en otros ordenamientos jurídicos, encontramos que en Argentina la Ley 24240 de 1993, en su artículo 40 regula lo concerniente a la responsabilidad objetiva frente a productos defectuosos afirmando:

Artículo 40. Si el daño al consumidor resulta del vicio o riesgo de la cosa o de la prestación del servicio, responderán el productor, el fabricante, el importador, el distribuidor, el proveedor, el vendedor y quien haya puesto su marca en la cosa o servicio. El transportista responderá por los daños ocasionados a la cosa con motivo o en ocasión del servicio. La responsabilidad es solidaria, sin perjuicio de las acciones de repetición que correspondan. Sólo se liberará total o parcialmente quien demuestre que la causa del daño le ha sido ajena. (El Senado y Cámara de Diputados de la Nación Argentina, 1993)

Teniendo en cuenta esto, se indican varios criterios que determina la ley de defensa del consumidor para establecer la responsabilidad objetiva y proceder a la reparación de los daños causados, tales como: 1) la legitimación por activa y pasiva; 2) el factor atributivo de responsabilidad; 3) eximentes de 
responsabilidad; 4) cargas probatorias y 5) al consumidor, por un daño ocasionado en responsabilidad solidaria.

Frente a la legitimación por activa y pasiva, la ley es clara en manifestar que la acción de daños puede ser empleada por todos los consumidores para exigir la responsabilidad, así como el pago de perjuicios ocasionados por los productores y distribuidores de bienes y servicios. Asimismo para el caso de la atribución de la responsabilidad se indica que esta es de carácter objetivo, es decir, que el elemento objetivo comprende no solo los defectos que pueden traer los productos que adquieren los consumidores sino que además incluyen los defectos que pueden darse en la prestación de un servicio.

A su vez la normativa presupone el caso fortuito como causal de ausencia de responsabilidad a favor del fabricante y distribuidor, siempre y cuando no exista un vínculo entre la causa que originó el daño y el resultado.

Respecto al desarrollo de las cargas probatorias, se indica que en el caso de la responsabilidad objetiva en los productos defectuosos, la legislación argentina prevee que la dinámica de la prueba está a cargo de los productores y distribuidores, dado que ellos controlan la cadena de producción de sus productos, por ende poseen la información acerca de la creación de bienes y servicios que en muchas ocasiones desconoce el consumidor. la Norma, la cual permite la indemnización debe dar a los consumidores, los artículos
1106 y 1107 explican que siempre y cuando la ley de orden especial requiera, los contratos deban ser por escrito, si en el contrato que suscribe el consumidor se incluye un soporte electrónico. Asimismo, si las partes emplean en sus relaciones de consumo medios electrónicos para su comunicación o celebración de contratos a distancia, el proveedor está en la obligación de informar al usuario, adicional a los preceptos contractuales establecidos y la acción de revocatoria de la oferta a la que tiene derecho, sobre los datos obligatorios para el uso adecuado de os medios electrónicos elegidos, para poder dimensionar los riesgos que se derivan de su uso y quien responde si se configuran los mismos.

6.2. Desarrollo jurisprudencial Colombia Corte Suprema de Justicia, Sala de Casación Civil

- Magistrado Ponente: Pedro Octavio Munar Cadena

- Radicado Nº Ref: Exp. 258993193992 19990062901

- Accionante: Margy María Manasse Vargas

- Accionado: Productos Naturales de Cajicá S.A., "La Alquería".

Antecedentes

ultrapasteurizada semidescremada, leche natural de la empresa "La Alquería".

Una vez con el producto en sus manos, abrió la bolsa, con la finalidad de consumir el contenido, y al realizarse esta acción, sintió que su órganos bucofaríngeos y su estómago se quemaban, al igual que un cosquilleo por su cuerpo y de inmediato una visión borrosa. De manera que debió ser trasladada al Hospital San Ignacio, centro médico que le practicó un procedimiento de intoxicación exógena al igual que unos examenes de toxología para determinar las causas de la enfermedad.

Después del incidente, la demandante persiste con los síntomas de visión borrosa, lo cual la lleva a realizarse exámenes de rutina, indicando que había disminuido su visión en un $70 \%$, así como el padecimiento de una enfermedad denominada desmielización, la cual según los criterios médicos se generó por la presencia de "agentes infecciosos y por las neurotoxinas, sustancias producidas por agentes bacterianos" (Sala de Casación Civil de la Corte Suprema de Justicia, 2009).

Consideraciones de la Sala

La Sala manifiesta que debido al avance tecnológico e industrial que se ha dado en la a demandante manifiesta que el día 31 de economía, la oferta de los bienes ha dado luagosto de 1999, envió a su hijo a comprar a gar a que se configuren grandes tendencias la tienda del lugar donde residía, un litro de en la sociedad de consumo masivo, lo cual leche larga vida. Este producto indicaba en genera una obligación al sistema jurídico y su empaque, que la leche que contenía era económico a responder por los retos y las 
garantías frente a esta realidad social cambiante.

De ahí que esta situación novedosa cree una brecha entre los productores y proveedores de bienes y servicios y los consumidores, por lo cual los fenómenos jurídicos desprendidos de la relación de consumo, no deben ser entendidos solo con las normas especiales, sino partiendo de los principios constitucionales de un sistema económico de libre competencia que permita la comercialización de productos y que a su vez proteja integralmente a esta parte débil en las operaciones de consumo.

Así desde este contexto el desequilibrio que se da en las relaciones de consumo es notorio, dado que aquellos que tienen como actividad económica la producción de bienes y servicios, son los que controlan la cadena de producción, debido al beneficio económico que esto le genera al igual que las ventajas negociales que se desarrollan en el mercado, mientras que los consumidores se dedican a la adquisición de bienes y servicios en aras de satisfacer una necesidad básica, lo que los coloca en un estado de vulnerabilidad.

Frente al caso en concreto, se resalta que la Corte Suprema de Justicia negó las pretensiones de la parte demandante, por cuanto esta no logró probar el nexo causal entre e hecho o la causa y el daño, en razón del consumo de la leche. Asimismo consideró que este producto no era defectuoso, dado que no se probó que contenía sustancias tóxicas que originaran un perjuicio a las personas que lo consumían.

\subsection{Desarrollo jurisprudencial argentina}

"Cataldo Federico Francesco contra Peugeot Citroen Argentina S.A. y otros sobre Ordinario"

Este caso de responsabilidad por producto defectuoso, se destaca por la compra por parte del demandante de un auto cero kilómetros en agosto del año 2003. Sin embargo en los días finales correspondientes al mes de febrero de 2004, el auto presentó incovenientes técnicos que representaron su detención en plena marcha.

De acuerdo a esto, el demandante acud en dos ocasiones al taller de la concesionaria para la solución de su problema. Un vez realizados los respectivos chequeos, el desperfecto en el auto persiste, lo cual lo lleva a comunicarse con la oficina de atención al cliente de Peugeot en Francia, par que se le brindara un servicio técnico telefónico, lo cual representó un tercer ingreso al taller para las reparaciones; pese a esto el daño continuó, por lo que demandó a los responsables en la cadena de producción comercialización por la violación a su derecho como consumidor, exigiendo el cambio del vehículo o la devolución del dinero, más la privación del uso y el daño moral.

Frente a esto la sentencia proferida por la Cámara Nacional de Apelaciones en lo Comercial, indica que este hecho está dentro del contexto de responsabilidad objetiva por el desperfecto de un producto que generó un perjuicio al consumidor
El Tribunal argumenta que aquellos que venden productos con ciertos manejos técnicos, donde usualmente los consumidores conocen la información transmitida para la venta y adquisición del producto, obliga a los productores y distribuidores a no defraudar todas las expectativas que el usuario tiene de bien. Así, de acuerdo al artículo 40 de la Ley del Consumidor, el régimen de responsabilidad objetiva por productos defectuosos se origina, cuando no se ejecutan de forma integral las obligaciones de comercializar bienes con unos estándares mínimos de calidad e idoneidad a favor de los consumidores.

\section{CONCLUSIONES}

Hay un caso reciente que es importante senalar. Los implantes mamarios PIP, producto creado por la empresa Poly Implan Prothése que posteriormente fue certificado por la empresa Alemana TÜV Rheinland, lo cua permitió la comercialización de las prótesis en diversos países del mundo.

Sin embargo, para el año 2010 se desató e escándalo donde se conoció que la empresa francesa no estaba utilizando el gel de silicona Nusil, producto autorizado para el relleno de los implantes mamarios sino un gel de silicona no autorizado el cual tendría grandes repercusiones en la salud de los pacientes, en caso de rotura. Asimismo la empresa alemana TÜV Rheinland, como entidad certificadora de la calidad de los productos, solo limitó su función a analizar los documento remitidos por el fabricante del producto pero no a revisar el producto en sí mismo, lo que permitió la distribución de miles de implan- tes defectuosos a nivel mundial, que colocaban en un riesgo inminente a los pacientes que utilizaran tal producto médico.

Dentro de los estudios realizados por las autoridades sanitarias en Francia se detectó que en el proceso de fabricación de los implantes PIP, se utilizó de forma no autorizada materia prima de baja calidad, especialmene silicona industrial para el relleno, mientras que en los documentos se soportaba que el material utilizado era un gel de silicona médica. De ahí que la preocupación frente al producto defectuoso radique en la seguridad que el mismo pueda ofrecer a los consumidores, el término de duración y el desarrollo de neoplasias (Maijers \& Niessen, 2012).

En Colombia el caso de responsabilidad por los implantes defectuosos fue llevado hasta el Tribunal de Comercio de Toulón por un grupo de abogados que representan los intereses de las mujeres afectadas. Así, para los años 2014 y 2017 el Tribunal internacional, sancionó a la empresa alemana TÜV Rheinland a indemnizar a las víctimas por su actuar negligente frente a la distribución y comercialización de los implantes mamarios en diversos países a nivel mundial sin que estos cumplieran con los parámetros de calidad requeridos.

En este sentido, se puede afirmar que el régimen de responsabilidad objetiva propende el resarcimiento de perjuicios a la víctima por un daño causado. En el caso del derecho en consumo en Colombia, este tipo de responsabilidad se configura por los productos defectuosos que se comercializan en el mer- 
cado y generan un riesgo a la integridad física de los consumidores.

La evolución de este régimen de responsabilidad desde la perspectiva del consumo, se da desde el Derecho anglosajón, especialmente por los avances jurisprudenciales que determinó Roger Traynor, Juez que indicó que los productores y proveedores eran responsables ante los consumidores por el riesgo que representa a la seguridad un producto defectuoso, por ende la responsabilidad es de carácter objetiva, por cuanto los fabricantes son los que controlan la cadena de producción y tienen los conocimientos especializados para analizar el defecto de un bien o servicio y que es estrictamente su responsabilidad en su circulación en el mercado.

En el contexto colombiano con la expedición de la Ley 1480 de 2011 o el Estatuto del Consumidor, se previó que responden solidariamente los productores y proveedores frente a los defectos de un producto que violenten el principio de seguridad y atenten contra la integridad física de un consumidor. De manera pues que los efectos de esta, irradian a todas las partes intervinientes en la cadena de producción y comercialización de los bienes y servicios. A su vez indica que el daño al consumidor surge del riesgo del bien o el servicio, por ende el productor, proveedor, distribuidor, vendedor o aquel que haya registrado su marca en el producto deberá responder solidariamente por el desperfecto del bien o la mala prestación del servicio que ocasionó un perjuicio patrimonial o afectó la seguridad del usuario.
Se resalta igualmente que es requisito indispensable que para que proceda la indemnización por los perjuicios causados, el consumidor deba probar el nexo causal hechos y el daño ocurrido como paso con el tema de los implantes PIP.

\section{REFERENCIAS}

Baudry-Lacantinerie, G. \& Saignat, L. (1908). Traité théorique et practique de Droit Civil. De la Vente et de l' echange (Troisiéne édition ed.). Paris: Librairie de la Socieété du Recueil.

Calais-Auloy, J. \& Steinmetz, F. (2006). Droit de la Consommation. Paris: Dalloz.

Coderch, P., Piñero, J. \& Rubí, A. (2003). Responsabilidad civil del fabricante y teoría general de la aplicación del Derecho (Lawenforcement). Universitat Pompeu Fabra.

Coleman, J. L. (2010). Riesgos y daños. Madrid: Marcial Pons.

Comunidad Europea (25 de julio de 1985). Directiva 374. Obtenido de Euro-Lex: http://eur-lex.europa.eu/legal-content/ES/ TXT/?uri=celex\%3A31985L0374

Congreso de Colombia (1887). Ley 57 de 1887. Obtenido de Código Civil: http://www. secretariasenado.gov.co/senado/basedoc/ codigo civil.htm

Congreso de la República de Colombia (12 de octubre de 2011). Ley 1480 de 2011. Obtenido de Secretaría del Senado: http://www. secretariasenado.gov.co/senado/basedoc/ ley_1480_2011.htm|\#20

Corte Constitucional de Colombia, C-1141 Demanda de inconstitucionalidad contra los (parciales) del Decreto 3466 de 1982 (30 de agosto de 2000).

Corte Constitucional de Colombia, C-973 de 2002 (M.P. Álvaro Tafur Galvis, 13 de noviembre de 2002).

Corte Suprema de Justicia, Sala de Casación Civil (M.P. Ricardo Hinestrosa Daza, 25 de noviembre de 1938).

Corte Suprema de Justicia, Sala de Casación Civil, exp. 3532 (M.P. Carlos Esteban Jaram lo Schloss, 1 de febrero de 1993).

De la Maza Gazmuri, I. (2009). Los límites del deber precontractual de información. Obtenido de Repositorio Universidad Autónoma de Madrid: https://repositorio.uam es/bitstream/handle/10486/3190/23023 maza_ $\%$ C3\%B1igo de la.pdf?sequence=1

Díaz-Ambrona Bajardí, M., Hernández DíazAmbrona, M., Pous De la Flor, M. \& Tejedo Muñoz, L. (2012). Derecho Civil en la Unión Europea (Quinta ed.). Madrid: Colex.

Díez Picazo, L. (1979). La responsabilidad civil hoy. ADC drid: Civitas.
ElSenado y Cámara de Diputados de la Nación Argentina (22 de septiembre de 1993). Ley 24240. Obtenido de http://servicios.infoleg. gob.ar/infolegInternet/anexos/0-4999/638/ texact.htm

Escola vs. Coca-Cola Bottling Co., 24 Cal. $2 d$ nia, 5 de julio de 1944).

Espinoza Apráez, B. (2015). La responsabilidad por producto defectuoso en la Ley 1480 de 2011. Explicación a partir de una obligación de seguridad de origen legal y constitucional. Derecho Privado, (28), 367-399.

Ghestin, J. (1983). Conformite et garanties dans la vente (produits mobiliers). Paris:

Giraldo López, A. (2014). Los conceptos de calidad, idoneidad y seguridad en el nuevo Estatuto del Consumidor. Con-Texto. Revista de Derecho Económico, 55-67.

Gutiérrez Santiago, P. (2006). Responsabilidad civil por productos defectuosos. Cuestiones prácticas 10. Granada: Comares.

Gutiérrez, P. (2011). El concepto legal de "defecto" en el régimen español y europeo de responsabilidad civil por daños causados por productos defectuosos. En Responsabilidad civil, derecho de seguros y filosofía del Derecho (Tomo I) (pp.657-706). Bogotá: Biblioteca Jurídica Diké

Larrosa, M. (2011). Derecho de consumo, protección legal al consumidor. Madrid: El Derecho Editores. 
Maijers, M. \& Niessen , F. (2012). Prevalence of rupture in poly implant Prostheses silicone breast implants, recalled from the European market in 2010. Plast Reconstr Surg, 129(6).

Mosset Iturraspe, J. (1993). Responsabilidad Civil. Buenos Aires: Hammurabi.

Mosset, J. \& Wajntraub, J. (2008). Ley de defensa del consumidor. Buenos Aires: Rubinzal Culzoni Editores.

Munar, P. O. (2013). La responsabilidad por productos, los grandes hitos de su evolución. En J. M. (Dirs.), Derecho del consumo. Problemáticas actuales (pp.173-212). Bogotá: Editorial Ibáñez.

Oviedo Albán, J. (2015). La Garantía por vicios ocultos en la compraventa. Bogotá: Temis S.A.

Parra Lucán, M. A. (1990). Daños por productos y protección al consumidor. Barcelona: José María Bosch Editor.

Rodríguez Olmos, J. (2013). “Deberes de protección, 'aun frente a terceros', en la dogmática alemana". Revista de Derecho Privado, (20), 301-346.

Sala de Casación Civil de la Corte Suprema de Justicia, Radicado N Ref: Exp. 258993193 99219990062901 (30 de abril de 2009).

Shina, F. (2014). Daños al consumidor. Bogotá: Astrea SAS \& Universidad de la Sabana.
Tamayo, J. (2007). La responsabilidad civil por productos defectuosos y su aseguramiento. En I. A. Estado, Responsabilidad Civil y del Estado. Medellín: Librería Jurídica Sánchez.

Ureña Carozo, B. (2015). Consideraciones sobre la responsabilidad civil por productos defectuosos en el marco europeo: Treinta años de la directiva 85/374/CEE. Panóptica, 10(2), 1-25.

Vásquez Pérez, E. (2015). ¿La responsabilidad por productos defectuosos es realmente objetiva según la Ley 1480 de 2011? Actualidad Jurídica, 7, 26-36.

Vázquez Bulla, C. (2014). La responsabilidad civil por productos defectuosos a la luz de la nueva Ley 3/2014: pasado, presente y futuro desde la perspectiva legal, doctrinal y jurisprudencial. Revista de Derecho UNED, (14), 717-750.

Villalba Cuéllar, J. C. (2014). La responsabilidad por producto defectuoso en el Derecho colombiano. Civilizar, 14(27), 17-40.

Villalba, J. (2012). Introducción al derecho del consumo. Bogotá: Universidad Militar Nueva Granada.

Woolcott, O. (2007). La naturaleza de la responsabilidad del productor a la luz del Derecho norteamericano. Prolegómenos, derechos y valores, 10(19), 125-148.

Woolcott, O. (2007). La responsabilidad del productor. Bogotá: Ibáñez. 